statement Dr. Barbor was provoked into making his astounding claim that in his hands only one in 300 cases required surgery, and into overlooking the fact that not only the title but the entire content of the broadcast indicated that it was concerned with, and confined to, disk lesions causing sciatica and not with the myriad varieties of backache which may or may not be due to disk disease and which may be helped by manipulation. The observation in the programme that about one in ten cases come to surgery was obviously seen to relate to patients with sciatica who had failed to respond to the conservative methods of treatment already demonstrated, and the proportion is I think a reasonable and generally accepted one. Nevertheless if Dr. Barbor can honestly confirm his statement that he is able to cure by his methods 299 out of every 300 patients suffering from protruded disk with sciatica then I shall accept that a manipulative Messiah has arrived amongst us.

I shall concede, however, that your two correspondents are correct in one respect, and that is in their commendation of the television series "Emergency Ward 10." To me the programme is notable for its technical accuracy, and it is evidently well counselled by its medical advisers. In passing I am pleased to learn that the lady with the slipped disk mentioned in that programme (Sister Young) is now recovering well as a result of bed-rest with the use of a surgical corset, and without following the advice of either Dr. Barbor or Mr. Armstrong.-I am, etc.,

\section{"Specialist Surgeon."}

\section{Typhoid Fever}

SIR,-In view of the recent cases of typhoid fever occurring in Britain and Switzerland, may I comment on some controversial aspects of this disease ?

1. Chloramphenicol.-I should like to stress how important it is that this drug should be given both early and for at least two weeks in typhoid fever. ${ }^{1}$ It is still the most effective drug in this disease, and I do not think its use should ever be withheld merely because of the small risk of aplastic anaemia. Chloramphenicol is obviously dangerous, as many authors, including Sharp, ${ }^{2}$ have pointed out, especially if used for long periods of time or in repeated doses. I agree, however, with Mr. W. D. Park (April 6, p. 950) and Dr. G. R. Royston (April 27, p. 1161) that the risks are overrated. Many of my own series of 1,300 typhoid patients were treated with chloramphenicol, and I have yet to see a case of aplastic anaemia due to this drug. Admittedly most of these patients were treated for two weeks or less, and this period appears to be reasonably safe. If chloramphenicol is given for less than $\mathbf{1 4}$ days in typhoid the relapse rate is greatly increased. It should also be pointed out that even with chloramphenicol there is a lag period of 36 to 48 hours before the response to therapy is seen. In the really toxic patient steroids should be given as well to diminish this delay and reduce the toxicity. Steroids should not be given in the routine case, however, due to the increased risk of intestinal perforation.

2. Value of T.A.B. ${ }^{3}$-Despite some fine work by the World Health Organization, I believe that T.A.B. is still only relatively effective, and that visitors to endemic countries should be warned of this fact lest a false sense of security be engendered. Some preparations of T.A.B. give less protection than others. This was shown in the case of alcohol-killed and preserved vaccine, which was found deficient despite its much vaunted high Vi content. I had to deal with one epidemic in Kenya with a high mortality and complication rate in which over $90 \%$ of the 700 victims had had alcoholized T.A.B. during the previous few months. ${ }^{4}$ T.A.B. is probably effective where the infecting doses of Salmonella typhi are relatively small. (It has yet to be proved effective in the paratyphoid fevers, perhaps due to the much higher infecting dose.) T.A.B. is certainly of less value where the infecting dose of typhoid bacteria is large, and perhaps the organism of a different strain from the one causing infection. I think that the dead vaccine will always prove to be relatively deficient in protective powers, and that the answer to this problem in future may be a living attenuated vaccine of several phage types.

3. Intestinal Perforation.-I think a timely warning should be given as to the dangers of operating on these cases. I feel that, with the exception of the acute perforation, diagnosed within six hours in the ambulant patient, treatment should be conservative with an Ochsner-Sherren regimen and large doses of chloramphenicol. ${ }^{15}$ In my series of 23 typhoid patients with either perforation or peritonitis, treated by this regimen, the mortality was $22 \%$ compared to most published mortality rates of $60-100 \%$ following operation. ${ }^{6}$ -I am, etc.,

Kampala, Uganda.

REFERENCES

1 Huckstep, R. L., Typhoid Fever and Other Salmonella Infections, 1962. Livingstone, Edinburgh and London.

- Sharp, A. A., Brit. med. J., 1963, 1, 735.

- Ibid., 1963, 1, 4.

- Huckstep, R. L., M.D. Thesis, Cambridge, 1957.

- Ann. roy. Coll. Surg Engl., 1960, 26, 207.

Bailey, H., Emergency Surgery, 1958, 7th edition, p. 208 Wright, Bristol.

\section{Typhoid Epidemics}

SIR,-In the B.M.J. of April 20 you published two articles on typhoid fever. In this country recently we have had more than 60 cases of this uncommon and distressing disease and the interest aroused has emboldened me to write some short notes about the typhoid epidemic we had in Bournemouth in 1936 when over 600 people were infected.

Very early in the epidemic diagnosis was made by blood culture and by growth on sugars. Two or three of the patients showed agglutinins to Bacillus aertrycke and to nothing else, but later these and the rest of the typhoid patients had $\mathbf{H}$ and $\mathrm{O}$ agglutinins. Throughout the epidemic it was thought that clinical severity, $\mathbf{H}$ agglutinins, and bacteriaemia showed no relation to one another.

Probably I saw about 200 patients. Into the general wards of a hospital the late Dr. Watson Smith, the late Dr. Robson, and I admitted 48 patients. We had our own beds, but the patients were common property. All patients received 3,000 calories a day and three died. In the various fever hospitals of the town we were given permission by the M.O.H. to examine the patients. It was noticeable that the convalescence in these patients was about two months longer than in ours, and we thought that this was because our patients had a more liberal diet. In addition I attended many patients privately and I saw several in consultations, but I could not be certain of what complications they might get, as I saw them once only.

Of the 200 patients one started with an acute appendix; four had a relapse, one with purpura, but 